\title{
TORNAR-SE OUTRO DE SI MESMO EM NARRATIVAS (AUTO)BIOGRÁFICAS DE PESSOAS COM ESCLEROSE MÚLTIPLA
}

\section{RAQUEL ALVARENGA SENA VENERA}

Universidade da Região de Joinville

RESUMO Este artigo é parte de uma pesquisa de pós-doutoramento intitulada "(Auto)biografias e subjetividades: o outro de si mesmo na Esclerose Múltipla", que buscou analisar os processos de subjetivação nas histórias de vidas de pessoas acometidas pela Esclerose Múltipla, organizadas em acervos em rede de Histórias de Vida do Museu da Pessoa, SP. Neste artigo busco entender, a partir de uma narrativa (auto) biográfica e da mobilização do conceito de tempo, como o sujeito se reconstrói após os sintomas e o diagnóstico da doença. A partir de Koselleck (2014), destaco os fatores sincrônicos e diacrônicos do condicionamento da consciência e percebo como as narrativas apresentam as mudanças do sujeito tornando-se outro de si mesmo. Quanto aos fatores sincrônicos, as narrativas dão conta do momento dos sintomas e diagnóstico até uma digressão para a acomodação da doença na vida. Quanto aos fatores diacrônicos, as eclusas da memória são alargadas, considerando também a narrativa anterior à doença, as identificações, os valores, a religião, o gênero, as escolhas preferenciais. Entendo que os fatores que formam a consciência, e que se mostram na narrativa, apresentam extratos múltiplos do tempo anterior à experiência com a doença, mas também dos efeitos desta, que continuam a transformar as subjetividades.

Palavras-chaves: Narrativas. (Auto)biografias. Subjetividades. Esclerose Múltipla.

ABSTRACT BECOMING ANOTHER OF HIMSELF IN AUTOBIOGRAPHICAL ACCOUNTS OF PEOPLE WITH
MULTIPLE SCLEROSIS

This article is part of a postdoctoral research entitled "Auto biographies and subjectivities: the other of itself in Multiple Sclerosis", which sought to analyze the processes of subjectivation in the lives of people affected by Multiple Sclerosis, organized in collections in Life Stories Network of the Museu da Pessoa, SP. In this article I seek 
to understand, from a biographical (self) narrative and the mobilization of the concept of Time, how the subject reconstructs after the symptoms and the diagnosis of the disease. Starting from Koselleck (2014), I emphasize the synchronic and diachronic factors of the conditioning of the consciousness and I perceive how the narratives present the changes of the subject becoming another of itself. As for synchronic factors, the narratives account for the timing of the symptoms and diagnosis until a digression for the accommodation of the disease in life. As for the diachronic factors, the memory locks are extended considering also the previous narrative the disease, the identifications, the values, the religion, the gender, the preferential choices. I understand that the factors that form the consciousness and that are shown in the narrative, present multiple extracts from the time before the experience with the disease, but also from the effects of this, which continue to transform the subjectivities.

Keywords: Narratives. Autobiographies. Subjectivities. Multiple Sclerosis.

\section{RESUMEN SE CONVIERTE EN OTRO DE SÍ MISMO EN NARRATIVAS AUTOBIOGRÁFICAS DE PERSONAS CON ESCLEROSIS MÚLTIPLE}

Este artículo es parte de una investigación de postdoctorado titulada "(Auto) biografias y subjetividades: el otro de sí mismo en la Esclerosis Múltiple", que buscó analizar los procesos de subjetivación en las historias de vidas de personas acometidas por la Esclerosis Múltiple, organizadas en Acervos en red de Historias de Vida del Museo de la Persona, SP. En este artículo busco entender, a partir de una narrativa (auto) biográfica y de la movilización del concepto de Tiempo, como el sujeto se reconstruye tras los síntomas y el diagnóstico de la enfermedad. A partir de Koselleck (2014), destaco los factores sincrónicos y diacrónicos del condicionamiento de la conciencia y percibo cómo las narrativas presentan los cambios del sujeto convirtiéndose en otro de sí mismo. En cuanto a los factores sincrónicos, las narraciones dan cuenta del momento de los síntomas y el diagnóstico hasta una gira para la acomodación de la enfermedad en la vida. En cuanto a los factores diacrónicos, las esclusas de la memoria se extienden considerando también la narrativa anterior a la enfermedad, las identificaciones, los valores, la religión, el género, las opciones preferenciales. Entiendo que los factores que forman la conciencia, y que se muestran en la narrativa, presentan extractos múltiples del 
tiempo anterior a la experiencia con la enfermedad, pero también de los efectos de ésta, que continúan transformando las subjetividades.

Palabras claves: Narrativas. Autobiográficas. Subjetividades. Esclerosis Múltiple.

\section{Uma introdução necessária}

La précarité n'est accident de la vie.

Elle lui est consubstantielle.

La vie est précarité.?

(LE BLANC, Guillaume, 2007, p. 61)

Se a afirmação da epígrafe é verdadeira, podemos supor que essa condição precária da vida é constantemente escondida pelas relações sociais, pelos vínculos, normas e regras de conduta que garantem uma ilusão de estabilidade. Vivemos mais tempo sob o efeito de um disfarce dessa precariedade através dos vínculos afetivos e sociais que criamos. As tragédias naturais ou as guerras, assim como as doenças crônicas e os acidentes abruptos, capazes de aniquilar a vida das pessoas próximas ou expor a fragilidade dela, são momentos em que o devaneio de estabilidade se esvai.

A experiência diante das condições impostas por uma doença crônica, como a Esclerose Múltipla, por exemplo, expõe a consciência da vida precária e do afeto que se coloca no limiar da vida e da morte - o desamparo. Essa condição humana pela qual nascemos, morremos e escapamos dela, a cada vínculo com os Outros, a cada amparo que buscamos, desde a relação materna; a cada relação social que estabelecemos, na ilusão de construir uma segurança que espante a precariedade da vida, torna-se algo insuportável para olhar de frente. Uma doença crônica traz a consciência da precariedade e obriga o sujeito doente a sentir novamente o

1 Tradução livre: "A precariedade não é acidente da vida. Ela é a mesma substância da vida. A vida é precária". desamparo pelo qual se esquivou por toda a vida através dos vínculos sociais que estabelece. Vladimir Safatle (2016) vai em Freud para dizer que existe em nós um desamparo ontológico, uma memória da vulnerabilidade da espécie e uma relação com o Outro que, ao mesmo tempo em que nos ampara, também nos despossui na medida em que nos faz sujeito. Nas palavras dele:

Como a vida humana desconhece normatividades imanentes, a afecção originária só pode ser, ao menos para Freud, a expressão da vulnerabilidade do sujeito no interior da relação com o Outro e da ausência de resposta articulada diante das exigências postas pela necessidade [...] a consciência da vulnerabilidade diante da força do outro, a herança filogenética da memória da vulnerabilidade da espécie na era histórica da glaciação ou, ainda, o sentimento diante da desagregação da visão religiosa de mundo [...] o desamparo passa da condição de 'dado biológico ordinário' para uma 'dimensão essencial, própria ao funcionamento psíquico'. (SAFATLE, 2016, p. 51-52)

As relações sociais, os vínculos afetivos que se desdobram do desamparo, como o medo ou a esperança, funcionam como cortinas de fumaça e nos dão a ilusão de que o que traz a vulnerabilidade, a dependência de um Outro do qual não temos controle, é uma condição externa ao corpo, como guerras ou doenças. Essa constatação se confirmou no decorrer da pesquisa de que trata esse artigo. A Esclerose Múltipla, EM, é entendida como uma doença autoimune na qual o próprio sistema imunológico dirige-se contra vários elementos celu- 
lares do sistema nervoso central. As pesquisas no campo da neurologia apontam que os sintomas da EM podem incluir perda de visão, visão dupla, rigidez espástica, fraqueza, falta de equilíbrio, dormência, dor, problemas no controle vesical e intestinal, fadiga, mudanças emocionais e comprometimento cognitivo de diferentes formas. Esses sintomas somados a um momento de vida - 16 a 60 anos, em que a família e a carreira estão em desenvolvimento - em que as escolhas são imperativas e especialmente em um contexto contemporâneo de exigências rápidas de expertise no mundo do trabalho, podem trazer, para os pacientes, significações tão negativas quanto a própria doença. Ver-se na condição de vulnerável, em um contexto de valorização das expertises, torna a condição psicológica e social do sujeito tão debilitada quanto a condição biológica. Ou seja, ouvir as histórias de vida dos pacientes pode dizer muito sobre a forma como pessoas comuns, homens e mulheres ordinários, significam a própria vida com uma limitação interna, sob o impacto do afeto do desamparo.

Esse artigo é, então, parte das reflexões produzidas durante a pesquisa pós-doutoral intitulada "(Auto)biografias e subjetividades: o outro de si mesmo na Esclerose Múltipla"2 que concordam com essa argumentação, qual seja, que o afeto do desamparo é uma condição humana, tanto biológica quanto psíquica, mas aflora em situações de vulnerabilidade e, por ser insuportável de ser sentido, passa a ser também disparador de políticas de amparo, políticas de medo e esperança, políticas de afetos que raramente são submetidas a crítica.

Embora essa pesquisa tenha analisado cinco narrativas de vida, produzidas em situação de pesquisa, esse artigo se debruçou apenas em uma dessas histórias. No decorrer das

2 O pós-doutorado foi realizado na Université Lille3, França, com o apoio de bolsa do Programa de Qualificação Docente da Universidade da Região de Joinville, UNIVILLE. análises, foi percebido que os momentos de maior impacto dos sintomas e do diagnóstico da doença coincidiam com um tipo de plasticidade narrativa mais tensa e com fissuras traumáticas. Os cinco entrevistados narraram uma biografia antes da doença bastante organizada, com planos de futuro sendo conquistados, e as dificuldades que apareciam valorizavam as vitórias alcançadas e, no meio a esse fluxo progressivo, onde a vida precária ou o desamparo não se mostram, o diagnóstico ou os sintomas da EM instalam uma tensão, uma fissura, uma frustração por tudo o que poderia ter sido. É um momento crítico, que funda novas configurações de percepções da própria vida e das expectativas de futuros possiveis e promissores.

Mas esse ponto de fissura, essa tensão não se instala com a mesma intensidade e de forma permanente na narrativa. Em algum momento, essas vidas foram ressignificadas e, ainda que a tensão, a frustração, ambas voltem por vezes a aparecer no decorrer das narrativas desses sujeitos, elas são mais intensas no momento sincrônico aos primeiros sintomas e ao diagnóstico. E essas análises perseguiram especialmente o momento em que os sujeitos ressignificam esse desamparo. É nesse ponto, no contato com a vulnerabilidade e com o afeto do desamparo, que a reflexão se faz. Como esses sujeitos diminuem o ponto de fissura entre a biografia da vida e a norma do discurso médico que instaurou para sempre o diagnóstico? O que foi feito subjetivamente para que as expectativas de futuro fossem reorganizadas? Como administraram o afeto do desamparo? Como transformam o afeto do desamparo em outros afetos mais suportáveis de sentir?

Como já anunciado, esse artigo traz parte dessas análises e usa como referência uma das histórias de vida coletada nessa pesquisa e trata-se da narrativa (auto)biográfica de um senhor chamado Ademir Pedro de Souza, com 
42 anos na época da entrevista e mais de 15 anos de diagnóstico de Esclerose Múltipla. Ele ficou nove anos sentindo os sintomas da doença e procurando em vários consultórios por um diagnóstico. Esse tempo de ausência de explicações para o seu sofrimento foi uma característica diferencial da sua história, com relação às outras quatro histórias narradas no mesmo período na pesquisa, e trouxe uma variável interessante: o diagnóstico que geralmente significa um marco na experiência com o afeto do desamparo, tornou-se para ele um grande alívio. Este artigo traz esse recorte, como diferencial da análise, ou seja, no caso específico do Sr. Ademir, o próprio diagnóstico foi a liberação subjetiva para o início da ressignificação da vida, em "condição crônica de doença" (SILVEIRA, 2016), ou seja, uma existência vulnerável.

A pesquisa a que se refere este artigo objetivou analisar, a partir do conceito tempo, os processos de subjetivação das pessoas acometidas pela Esclerose Múltipla, nos discursos (auto)biográficos, visibilizando-as como práticas educativas e patrimônios culturais, no entanto, em um desdobramento bem mais modesto, se propõe mostrar, a partir da narrativa de vida do Sr. Ademir, como as referências estruturais da sua vida, narradas no tempo anterior à doença, foram usadas como ferramentas para o fluxo de uma nova subjetivação, liberta do efeito paralisante do tempo sincrônico ao diagnóstico, mas jamais desconectado dele e do afeto do desamparo ou da condição vulnerável que se instalou.

O Sr. Ademir faz parte dessas cinco pessoas, dois homens e três mulheres, que tinham cerca de 40 a 60 anos, na época da entrevista, e haviam recebido o diagnóstico há aproximadamente 15 a 20 anos. As cinco histórias possuem suas diferenças, mas, com as devidas ressalvas, em síntese, podem ser apresentadas da seguinte forma: a partir do diagnóstico, os pacientes são envolvidos em um discurso médico científico sobre a EM que Ihes explica uma doença rara, degenerativa, progressiva, incurável e com potencial incapacitante. A essa altura, o corpo desse sujeito já sentiu, em alguma medida, os sintomas incapacitantes da doença e esse impacto é o momento em que sua biografia encontra a norma do discurso médico que o coloca em outro lugar. A partir desse momento, ele é e sempre será um sujeito que carrega consigo algo que o degenera.

Eles ouvem do discurso médico as incidências da maioria dos doentes: alguns médicos chamam o grupo de pacientes com EM de "grupo alfa", ou seja, os doentes são pessoas proativas, a grande maioria possui ensino médio ou curso superior completo, são economicamente ativos, e estão envolvidos em projetos de sucesso e muito estresse, no momento do diagnóstico e nos surtos e crises posteriores. comum relatarem, como paráfrase do discurso médico, o que ouvem sobre suas características: que são pessoas sistemáticas, metódicas, organizadas e, portanto, suscetiveis a um maior nível de frustrações e estresse. Mas nenhuma dessas incidências significa uma estabilidade acerca dos motivos dos surtos da EM e nenhuma comprovação científica sobre os disparos da doença. No entanto, esse discurso oferece aos doentes um lugar de onde passam a se ver, sensiveis a situações de estresse. Ainda que não se saiba o que dispara a doença, mas se essas características são comuns nos doentes, elas dão pistas de que algo não está bem. São características que, em grande medida, funcionam como explicações sociais sobre qualquer sucesso: são focados, metódicos, sistemáticos, possuem uma exigência de alta performance, muitos são empreendedores, líderes, articulados em seus grupos, proativos. Mas, paradoxalmente, possuem uma doença degenerativa que pode ser acionada pelo estresse que esses comportamentos produzem. 
Em outra frente, esse mesmo discurso médico oferece o prognóstico que vem do discurso farmacêutico. Existem remédios que atrasam a degeneração neurológica, outros que tratam os casos de surtos. A partir do envolvimento com esses discursos e com a experiência diária com algum tipo de limitação, efeitos colaterais da medicação, novidades físicas que forçam algum tipo de adaptação, as narrativas vêm recheadas de momentos entre negação completa, depressões em todos os níveis, busca de informações, adaptações aos limites, buscas de autoconhecimento, e, por fim, uma necessidade muito grande de contar sobre uma suposta "superação". As revistas produzidas pelos laboratórios trazem uma carga de conteúdos com sentidos de "superação" e esses discursos aparecem repetidos nas narrativas.

Em alguns momentos, essas histórias narram o limite corporal em que o "eu" procura reconhecer-se a si mesmo com a EM e se depara com algo irreversivel, irreparável, um luto da expertise e da rapidez em que se conhecia. Nessa experiência, esse "eu" constrói algo que só foi possivel na relação com a doença e com o próprio limite. Esse momento é libertador e é esse o ponto que essa análise se interessou e perseguiu. 0 que faz com que as subjetividades construídas após o diagnóstico da EM não se resumam a um assujeitamento completo às normas, mas também se ressignifiquem? o que faz com que essas normas do discurso médico não sejam acolhidas totalmente, mas se tornem novas normatividades? O que fazem com o desamparo em que a doença os coloca? Esse movimento narrativo, aconteceu em maior ou menor clareza nas cinco narrativas, e nesse artigo será mostrado apenas a partir da narrativa do Sr. Ademir, como já foi anunciado anteriormente.

Para apresentar parte das reflexões da narrativa (auto)biográfica do senhor Ademir, esse artigo se organiza, em um primeiro momento, apresentando um pequeno percurso metodológico da produção dessas histórias de vida, inspirado na Tecnologia Social da Memória, sistematizada pelo Museu da Pessoa (2009), especialmente como ele aconteceu com o Sr. Ademir e como a sua narrativa foi se fazendo. Em um segundo momento, apresenta como os conceitos tempo foram entendidos, a partir de Ricoeur (1999) e Koselleck (2014), as subjetividades, com Guattari e Rolnik (1999), norma e normatividade a partir de Canguilhem (2009) e, sobretudo, a partir da experiência com a EM. Em um terceiro momento, apresento a análise da história de vida do Sr. Ademir. Nesse artigo, foram destacadas a consciência da precariedade da vida trazendo o afeto do desamparo, mas acima de tudo, a partir dele, acionando uma potência que faz virar uma chave para uma nova subjetividade.

\section{A produção de uma História de vida}

Como anunciado na introdução, as análises apresentadas nesse artigo foram desenvolvidas na pesquisa do pós-doutorado intitulada “(Auto)biografias e subjetividades: o outro de si mesmo na Esclerose Múltipla". No entanto, o percurso metodológico de produção dessas narrativas de vida é anterior. Trata-se da pesquisa que produz o primeiro acervo de Histórias de Vida de pessoas com Esclerose Múltipla, intitulado: “Memórias Múltiplas e Patrimônio Cultural em rede: o desafio (auto) biográfico diante da ameaça da perda". ${ }^{3}$ Uma aposta na existência de um acervo contínuo, ou seja, de uma pesquisa que não aponta um recorte quantitativo. Ela está aberta, enquanto existirem pessoas que desejem doar suas histórias. A referida pesquisa de pós-doutorado

3 A referida pesquisa que coleta e produz o acervo de Histórias de Vida de pessoas com Esclerose Múltipla foi aprovada pelo Comitê de Ética em Pesquisa, CEP, através do Parecer Consubstanciado 993.242, relatado em 27/03/2015. 
trabalhou com cinco narrativas (auto)biográficas, que foram as primeiras gravações, em áudio e vídeo, transcritas em textos. Foram histórias coletadas a partir de uma entrevista semiestruturada com o método da História Oral de Vida, em situação de pesquisa, que serão publicadas no acervo do Museu da Pessoa no Brasil. ${ }^{4}$

A escolha pelo método da História Oral de Vida e a parceria com o Museu da Pessoa levou em conta o desejo de contribuir para a democratização da memória social e evidenciar os cotidianos de pessoas comuns que constroem sentidos em suas histórias e podem ser agentes transformadores das relações sociais. Desta forma, a proposta do método da História Oral de Vida, também utilizada pelo Museu da Pessoa, não se vale de pseudônimos para nomear os sujeitos da pesquisa, a menos que esse seja um desejo manifesto pelos entrevistados, como são os casos de histórias envolvidas em violências ou exposições que comprometam a integridade da vida. Antes, visibilizam às pessoas, com seus nomes reais, referências territoriais e cotidianas. 0 método busca especialmente evidenciar que pessoas fazem suas histórias, além das narrativas oficiais e compõem uma história do seu tempo. É a evidência dos sujeitos em seu tempo e história.

Outro detalhe específico dessa pesquisa é o fato de que todos os dados produzidos - em textos transcritos, vídeos e imagens cedidas pelos sujeitos - estão disponiveis na rede mundial de computadores e fazem parte de um acervo museológico. Dessa forma, não serão descartados em um espaço de tempo

4 O acervo do Museu da Pessoa é contínuo, porém essas cinco primeiras histórias que abrem a curadoria foram lançadas em 25/08/2017 compondo um dos eventos da campanha "Agosto Laranja", que divulgou a conscientização da Esclerose Múltipla no Brasil. As cinco primeiras histórias abriram a curadoria, porém novas histórias de vida de pessoas com EM estão sendo preparadas, tornando o acervo sempre aberto à continuidade do trabalho. pós-pesquisa, como comumente se faz. Antes, serão disseminados e consumidos por leitores interessados ou outros pesquisadores, com outras questões, que podem ser alheias àquelas pensadas quando da elaboração do acervo.

É importante registrar que essa pesquisa possui uma característica intersubjetiva entre a pesquisadora e os pesquisados. Como em toda pesquisa (auto)biográfica, como destaca Delory-Momberger (2016, p. 142), existe “[...] uma relação interpessoal complexa e recíproca, na qual o pesquisador é ele próprio um 'pesquisado' [...] é um conhecimento a dois que se constrói em uma interação, em uma intersubjetividade", muito embora essa condição não seja muitas vezes consciente entre os envolvidos. Nesta situação específica, todos os envolvidos na equipe, com exceção dos estudantes bolsistas, ou eram diagnosticados com EM ou era o médico neurologista que acompanha essas pessoas e também é pesquisador. Essa condição, por um lado, facilitou o encaminhamento das entrevistas, uma vez que os sujeitos estavam confortáveis e em vínculos de confiança, afinal compartilhavam a mesma vulnerabilidade. Por outro lado, exigiu uma rigidez teórico-metodológica que foi assegurada pelo compartilhamento e a intervenção de um olhar externo, durante as atividades do pós-doutorado. ${ }^{5}$

0 fato da pesquisa ter sido anunciada por uma pesquisadora, diagnosticada com Esclerose Múltipla, e por um médico neurologista, com bastante legitimidade e confiança entre seus pacientes, tornou o espaço da investigação um lugar de afetividade. Após os acertos de agendamento e os acordos para a entrevista, os sujeitos convidavam a equipe para uma visita em suas casas. Dos cinco entrevistados, três apresentavam limitações de mobilidade e duas moravam a uma certa distância, assim

5 Esse olhar externo foi gentilmente concedido pelo colega Dr. Christophe Niewiadomski, da Université Lille3. 
preferiram receber a equipe a ir ao encontro dela, em estúdios da universidade.

Em especial, o Sr. Ademir recebeu a equipe em sua casa, em três sessões de entrevistas e uma visita. Cada sessão durava cerca de três horas e era mediada por duas entrevistadoras com o roteiro semiestruturado, duas câmeras com três equipamentos de filmagem e um de captura de áudio. Em todas as três sessões, a equipe foi recebida com uma mesa posta, com café, leite e bolo produzidos por ele. As xicaras, pratos e talheres eram simetricamente organizados e esse dado foi registrado nas anotações da pesquisa. $0 \mathrm{Sr}$. Ademir recebia a equipe, sempre muito simpático, acolhedor, e mostrava ser sistemático com a organização da casa, nos detalhes da mesa, no capricho com que mostrava o quintal, o jardim. Sentados todos à mesa, ele narrava sua história, mediado pelas perguntas das entrevistadoras, e, por vezes, tensionava os ombros e a musculatura do rosto. Externava o desejo de ver sua história contada linearmente e com beleza. Precisava ser perfeita e, ao final da terceira sessão, ele revelou à equipe que o desejo de publicar sua História de Vida também era para ser como um presente para a esposa. Depois que soube do diagnóstico da EM, ele desejou registrar sua história para deixar para a posteridade, mas também para outras pessoas que fossem diagnosticadas com EM saberem que é possivel viver uma vida. Adaptada, mas uma vida com qualidade. Ademir narra como um testemunho, narra como um presente de gratidão à esposa.

Após as entrevistas semiestruturadas, Ademir ainda recebeu parte da esquipe para mostrar mais sua casa, sua rotina e conversar sobre a vida. E após as transcrições dos áudios em textos, uma nova visita foi realizada para ler e revisar a narrativa, quando foram acertados detalhes e nomes citados, assim como decididos a retirada e ou acrés- cimo de alguns trechos. ${ }^{6}$ Em sintese, sua história diz que o sr. Ademir Pedro nasceu em 22 de fevereiro de 1974, é o primeiro filho de um casal como tantos outros que sonham em ter uma família cristã, honesta, modesta e saudável. Sempre foram moradores de Joinville/SC, mas atualmente apenas ele mora na cidade, os demais estão em uma casa na praia. O casal teve Ademir ainda muito jovem e logo depois a irmã caçula. Ele se emociona em lembrar dos carinhos da mãe, do colo que ainda parece quente em suas lembranças. Essas lembranças "são azuis", ele diz, a cor que metaforicamente o acaricia enquanto lembra. O pai, ele admira por ser "um homem que nunca reclama de nada", com preceitos de honestidade e verdade que marcaram a vida do filho. Conta o pouco que sabe da sua ascendência híbrida, do bisavô e da bisavó alemães, dos avós miscigenados e dos pais estereotipados como brasileiros. $\mathrm{O} \mathrm{Sr}$. Ademir lembra que a família viveu um problema de saúde bastante sério com a irmã, ainda quando muito bebê. Ele se recorda do padre em casa e de todos esperando a morte da criança, lembra dos pais chorando muito e dos seus sentimentos confusos. Mas, ao narrar esse episódio, ele reforça os laços da família, a amizade verdadeira entre eles ainda hoje. É uma lembrança que vem no contexto de afetos diante da quase perda da irmã e da percepção infantil da importância da família, reforçando que, no presente, apesar de seus parentes morarem em outra cidade, estão em contatos virtuais todos os dias. Como outros moleques da sua idade, brincou na rua com os vizinhos, jogou bola na quadra do bairro, fez peraltices que o pai só veio a saber mui-

6 A devolutiva final foi realizada no dia 25/08/2017, com a publicação do acervo de Histórias de Vida no Museu da Pessoa, com a presença da família, acadêmicos da universidade, entrega das gravações em DVDs e agradecimentos públicos pela contribuição com a escrita de parte da história da Esclerose Múltipla. 
tos anos depois. Iniciou-se no mundo do trabalho ainda muito jovem contra a vontade do pai, que desejava que ele terminasse os estudos. Mas o desejo de consumir, como os amigos mais velhos, o colocou em uma fábrica metalúrgica aos 15 anos. Em seguida, descobriu o trabalho no comércio, em uma loja de autopeças, e se realizou vendendo peças de carros e conversando com clientes. Na adolescência, saía para dançar, para paquerar e seus olhos azuis faziam sucesso, e foi entre essas experimentações que conheceu sua esposa - mulher a quem atribui o seu grande amor. Antes dos 20 anos, ele descobriu uma grande paixão e lembra com doçura o tempo em que saíam de moto, com outros casais de amigos, para a beira do rio, na área rural de Joinville. Foi com essa mulher que, também muito jovem, se tornou pai de duas filhas e ao lado dela construiu seu patrimônio. A gravidez da namorada acelerou o casamento e, a princípio, morou nos fundos da casa do pai, depois comprou um terreno em um bairro mais afastado do centro e foi construindo uma casa aos poucos. Sobre esse passado, lembra que se sentia muito seguro de si, gostava de andar de bicicleta, era ágil e desejava ter seu próprio negócio. Morou dentro da construção, trabalhou sem limites e terminou a casa. Foi nesse tempo, logo depois do casamento, em meio a essa construção inicial da vida, que ele começou a sentir os sintomas da Esclerose Múltipla, mas ficou sem o diagnóstico por quase dez anos. Caía sem entender o porquê, tinha dificuldades para pedalar a bicicleta, sofria com fadigas, nas noites de verão, na casa em construção, "que era um forno", ele conta. Não entendia por que sentia mais calor que os outros, formigamentos pelo corpo e uma sequência de noites maldormidas. Sentia que não tinha mais velocidade e equilíbrio na loja de autopeças onde trabalhava e frequentemente deixava as pe- ças cair, quando ele mesmo não caía. Sentiase, por vezes, constrangido, entre os colegas de trabalho, que por vezes diziam que ele estava bêbado.

Mesmo com tantas dificuldades, terminou a casa e montou seu próprio negócio. Mas as coisas não foram bem e, fragilizado, não conseguiu ser o empresário de sucesso que sonhou até vender a loja e se tornar novamente um funcionário. Passou por muitos médicos, fez inumeráveis exames e recebeu alguns diagnósticos que levaram a terapias ineficazes. Até que veio o diagnóstico que foi significado como um alivio. Ele ouve falar de diagnósticos que funcionam como um "divisor de águas" na vida das pessoas, mas, na sua história, o diagnóstico funcionou como um "grande alívio", afinal, ele precisava de uma explicação para tantos limites em um corpo tão jovem. Dois anos depois, o Sr. Ademir se aposentou e, no momento da entrevista, morava nessa mesma casa que foi construída com tanto esforço, com a esposa e as duas filhas. Uma delas estava noiva e ele se orgulhava com o início da sua vida adulta, com a compra de um apartamento próximo ao endereço da família. As três mulheres da sua vida trabalhavam durante todo o dia e ele ficava em casa cuidando vagarosamente de cada detalhe. Por vezes, protagonizava algum acidente doméstico, mas enquanto se narra não se vê dependente de cuidador. Metódico, sistemático, ele cuida do jardim, do quintal, da casa e principalmente da cozinha, onde recebia a equipe para as entrevistas, com muito agrado. Faz da cozinha seu lugar de prazer e cuidado da família. É ali que agrada as filhas e a mulher, quando prepara as tapiocas do café da manhã, a batata doce para a filha, as experimentações de receitas que ele descobre em um canal de TV ou na internet. O Sr. Ademir inventa receitas com as frutas do quintal e faz dos bolos e pratos que prepara a alquimia da própria vida. 
Tempo, subjetividades, norma, normatividade e a Esclerose Múltipla

Existia desde o início da pesquisa uma hipótese de que, ao organizar temporalmente as narrativas em eclusas de memória, seria possivel tornar visivel uma chave para localizar as ressignificações subjetivas dessas pessoas. Ao organizar uma narrativa de vida no tempo sincrônico e diacrônico da doença seria possivel identificar as ferramentas, as possibilidades de subjetivação de vidas, a partir dos discursos e experiências com a doença. A doença interfere na sensação temporal presente/futuro e intensifica o desejo pelas narrativas presente/passado. Os deslocamentos nas sensações temporais permeiam as subjetividades construídas a partir dos discursos sobre a doença, ou seja, o afeto do desamparo elimina a sensação de temporalidade necessária para perspectivar futuros, por exemplo. Então, seria na dimensão temporal das narrativas que estaria a resposta da incógnita subjetiva. Como essas vidas se subjetivam a partir dos discursos sobre a doença? Como nesse movimento de subjetivação, essas pessoas se tornam "assujeitadas" a essas normas, mas, também, como se subjetivam de outras formas?

Como pensar as narrativas de vida a partir do tempo? Essa análise está em concordância com Paul Ricoeur (1999), quando ele aproxima e até mesmo funde a memória ao tempo, "La memoria es del tiempo", ' ele diz (RICOEUR, 1999, p. 13), as narrativas de memórias fazem aparecer o tempo. 0 tempo sem a narrativa se esvai, não tem forma. Só temos acesso ao tempo pelas narrativas de memória. Ou, por outra perspectiva, sem o tempo, as narrativas tornam-se ilegiveis.

O diálogo com Ricoeur (1999) ampliou as possibilidades de percepção do tempo nas

7 Tradução livre: Memória é tempo. narrativas de vida da pesquisa que, em grande medida, estiveram marcadas pela linearidade do começo da vida orientada pelo nascimento, origem da família, infância, juventude, vida adulta... até o presente. Embora o roteiro semiestruturado da entrevista sugerisse esse direcionamento, elas apresentaram a evidência de que existem em uma narrativa de vida uma multiplicidade de tempos em um mesmo tempo. E o argumento para essa afirmação é que as narrativas de memórias de vida se iniciaram a partir da demanda trazida pela ameaça da perda da memória e das faculdades humanas de mobilidade, linguagem e outros sentidos, ou seja, pelo presente. Dessa forma, percebeu-se que o fio latente da origem da história da vida desses sujeitos coincide com o lugar de luto deixado pela doença e não pelo nascimento. Especialmente o Sr. Ademir, depois de narrar um pouco sobre seus pais, sua família e infância, anunciou que gostaria de narrar a partir do encontro com os sintomas da EM. Isso significa dizer que lembrar o passado, tornar o passado presente, só importa a partir de demandas existenciais do presente, tendo em vista as expectativas de futuro, construídas em função também do presente.

A afirmação de que memória é tempo produz um sentido surpreendente ao próprio tempo que se faz ver a partir dos gestos narrativos que organizam as lembranças em um fluxo entendível. A Esclerose Múltipla, por ser uma doença altamente incapacitante, sem uma marcação biológica, portanto imprevisível, sem cura e ainda de difícil interpretação médica, escancara o afeto de desamparo no sujeito e interfere na sua organização temporal. Os desdobramentos que o sujeito elabora com o afeto do desamparo, como transformá -lo em medo ou esperança, dispara sensações temporais expressas nas narrativas - tanto para "romantizar" um passado sem a doença quanto para perspectivar um futuro. 0 presen- 
te é marcado pelas demandas e experiências físicas com a doença, seu futuro, ou melhor, suas expectativas de futuro são incertas e obscurecidas e o que resta de mais seguro são as memórias do passado, da vida vivida sem a doença.

Nesse aspecto, é possivel afirmar que existe uma experiência temporal comum entre os pacientes? É Reinhart Koselleck (2014) que ajuda a pensar a questão. Ao analisar as memórias da guerra, ele oferece ferramentas de análise possiveis para perscrutar as subjetividades produzidas nesse jogo de consciência/ percepção temporal. Segundo ele, "a biografia de qualquer ser humano contém rupturas que parecem abrir um novo período na vida" (KOSELLECK, 2014, p. 247) e as experiências bruscas forçam o sujeito a abandonar caminhos comuns e abrir novas possibilidades. Ele dizia sobre a guerra, mas analogicamente esta análise se apropria do argumento para pensar a Esclerose Múltipla, uma doença rara, crônica, sem cura, degenerativa e incapacitante, como outra experiência brusca. A ideia das "eclusas da memória" amalgama a experiência temporal a partir da doença, com as releituras dos conceitos de memória e subjetividade.

E foi nesses arranjos de tempo que essa análise ancorou sua aposta para entender o processo de subjetivação a partir da doença. Ao invés de "sujeito", assume-se um campo de "subjetividades políticas", e este pressupõe uma multiplicidade de agenciamentos. Seria coerente pensar que nesse campo coexistem: a) a infância (AGAMBEN, 2005) - aquele indivíduo que fala, possui o domínio do código linguístico e, ainda assim, estará sempre se deparando com a experiência babélica de novos signos de sua cultura ou estará sempre convivendo com a privação da linguagem; b) o indivíduo seriado (GUATTARI; ROLNIK, 1999) - produzido pelas máquinas capitalísticas e, ao mesmo tempo, disciplinado pelas institui- ções estatais, que provocam a individuação do corpo, capaz de fixá-lo como terminal consumidor; e c) um campo de subjetividades marcadas pelas necessidades do tempo histórico vivido e modeladas no registro do social.

Explicando melhor, as narrativas que foram coletadas na pesquisa visibilizaram subjetividades que, ainda que na fase adulta, detentoras do domínio do sistema de linguagem de sua cultura, no momento do aparecimento dos sintomas, era como se infantilmente não soubessem decodificar aqueles sinais. Os sintomas da doença tornam o corpo irreconhecível por ele mesmo. Essa subjetividade, já disciplinada nos discursos institucionais acredita nas promessas do conhecimento médico ou na esperança divina. Elas recorrem aos consultórios médicos, se submetem a exames, leem revistas, livros, entregam para Deus, fazem correntes de orações na medida da sua fé. Elas são terminais de consumo desses discursos e se curvam, em alguma medida a eles, e diante das experiências com os sintomas, com a limitação corporal diária, elas se adaptam ou não, ressignificam em maior ou menor medida. Essas subjetividades se fazem a partir do presente, do passado e da possibilidade de projetar futuros possíveis.

Essa reflexão permite interpretar, nas análises das narrativas, as subjetividades que agenciam enunciados em dois movimentos possiveis. No primeiro, essa subjetividade permanece submetida aos discursos tal como os recebe, assumindo a "alienação e opressão", como proposto por Guattari e Rolnik (1999). No segundo movimento, ela se reapropria dos componentes da subjetividade, valendo-se da expressão e da criação, e vive o "processo de singularização". Esses dois movimentos são intercambiáveis em um mesmo corpo e "duplamente descentrados". Considerando essa descentralização constante, pode-se afirmar que o segundo movimento - 
"processo de singularização" - é imanente ao primeiro movimento - "processo de subjetivação". Essa imanência justifica a preferência conceitual dos autores entre ideologia e produção de subjetividades. Ao trocar o conceito tradicional da linguagem por "agenciamento coletivo de enunciação", Guattari e Rolnik (1999) estão considerando que, apesar dos sistemas de equivalência e de tradutibilidade estruturais incidirem nos pontos de singularidade em processos de singularização que são as próprias raízes produtoras da subjetividade em sua pluralidade, a singularização se assemelharia ao momento em que o "sujeito falante" cria outros sentidos para os signos, desliza os sentidos fixados. Seria, ainda, a utilização da potência humana de negociar sentidos no limiar da privação da língua, no local das tensões entre o signo e a semântica, entre o saber e o movimento da história.

Esses dois movimentos do processo de subjetivação podem ser lidos em situações de doença e saúde, a partir dos estudos de Georges Canguilhem (2009). Em 1943, ele publicou a obra Le normal e le pathologique, porém anos mais tarde ele vai reeditando-a com enxertos de textos, notas e revisões, que foram sendo desdobrados na continuidade de sua investigação. A 6a edição, traduzida para o português, traz textos posteriores. Nesse trabalho, Canguilhem (2009) refaz o sentido de saúde e doença, de normal e patológico, argumentando contra um sentido ontológico da doença como oposto à saúde e algo que vem a partir do ser normal ou saudável. Nas palavras dele:

[...] confrontamos a concepção ontológica da doença, que a entende como o oposto qualificativo da saúde, e a concepção positivista, que a deriva quantitativamente do estado normal. Quando a doença é considerada como um mal, a terapêutica é tida como uma revalorização; quando a doença é considerada como uma falta ou um excesso, a terapêutica consiste em uma compensação. (CANGUILHEM, 2009, p. 126)
Seu argumento vem ao encontro da epígrafe desse texto, que afirma ser a vida precária. Nessa direção, ele diz que o patológico faz parte do normal e vice-versa. Ter saúde é estar susceptível a um erro biológico e passivo a adoecer. A norma, criada com critérios positivistas acabou gerando problemas sociais mais abrangentes que a própria doença. Um desses problemas é a responsabilização do doente como um sujeito que não obedeceu à norma dos cuidados com a saúde, por exemplo. Deslocar essa perspectiva de sentido do normal como uma média estatística, permite entender que a doença "deixa de ser maldição para ser malentendido [...] A doença deixa de ter qualquer relação com a responsabilidade individual. Não há mais imprudência, não há mais excesso a recriminar, nem mesmo responsabilidade coletiva, como em caso de epidemia" (CANGUILHEM, 2009, p. 124).

Essa análise entendeu que as subjetividades, como máquinas de consumo, estão expostas a esse tipo de norma do discurso médico que contrapõe binariamente a doença e a saúde, o normal e o anormal. Receber um diagnóstico de uma doença degenerativa e progressiva, sem cura e indeterminada como a EM, é perder a certeza de sua normalidade. A norma médica desloca o sujeito da posição de normal e o decreta ao conjunto dos doentes. E esse sentido socialmente construído pode dificultar a elaboração que o sujeito faz sobre sua nova existência. "A doença do homem normal é o aparecimento de uma falha na sua confiança biológica em si mesmo" (CANGUILHEM, 2009, p. 131). Nesse sentido, ao consumir esses enunciados, essa perda de confiança biológica em si mesmo é contemporânea do afeto do desamparo. No caso dessa pesquisa, observou-se nas narrativas o aparecimento de depressões ou uma paralisação das expectativas de futuro, no fluxo da vida. Esse assujeitamento faz parte do processo de subjetivação, 
no entanto, tanto Canguilhem (2009) quanto Guattari e Rolnik (1999) apontam um segundo movimento. Guattari e Rolnik (1999) chamam esse segundo movimento de singularização e Canguilhem (2009) traz a possibilidade de uma normatividade. Nas palavras dele, "chamamos de normatividade a capacidade biológica de questionar as normas usuais por ocasião de situações críticas, e propusemos medir a saúde pela gravidade das crises orgânicas superadas pela instauração de uma nova ordem fisiológica" (CANGUILHEM, 2009, p. 130). Dessa forma, ele não se opõe à existência de uma norma na existência da vida, antes a defende, desde que considere o movimento humano de resiliência. Não apenas assujeitados às normas sociais, como sugere o dispositivo teórico de análise a partir de Guattari e Rolnik (1999), mas construtores de novas adaptações e normatividades para si. Capazes também de recriarem as próprias normas constituídas nos agenciamentos coletivos de enunciação.

\section{Um outro de si mesmo ou o desamparo feito esperança... e medo}

O primeiro passo metodológico para a análise das narrativas de vida foi separá-las em três momentos temporais ou três eclusas de memória. No primeiro momento, ou um tempo anterior à doença, na primeira eclusa, foram separadas as narrativas que contaram sobre a vida do sujeito antes da doença. Experiências com os pais, como foi a infância, percepções referenciais de mundo geralmente apareceram nesse momento. Em um segundo momento, foram separadas as narrativas que contaram sobre o início dos sintomas, o diagnóstico e como reagiu a essa nova realidade. Esse tempo foi chamado de narrativas sincrônicas à doença. $E$, em terceiro e último momento, foram separadas as narrativas que contaram sobre como a vida foi se assentando, como estão hoje as novas adaptações. Aqui apareceram revisões da memória narrada na primeira eclusa, autojulgamentos, as digressões da vida. Esse momento foi chamado de narrativas diacrônicas. Entre a segunda e a terceira eclusa, a análise perseguiu algo que funcionou como chave para perspectivar futuros, algo que abriu as comportas e o fluxo da vida seguiu se refazendo.

\section{A primeira eclusa}

O Sr. Ademir Pedro de Souza tinha 42 anos quando narrou sua história de vida. Ele recebia a equipe de pesquisa apoiado em sua muleta, na porta de sua casa. Ela era sempre muito organizada e limpa. Convidava a todos para sentar na sala de estar e, depois, encaminhava a equipe para a cozinha, onde recebia com a mesa posta com sinais de muito cuidado na preparação. Ele estava sempre sozinho e fazia questão de dizer que estava bem para cuidar de si mesmo. Falava com carinho da sua esposa e filhas, que trabalhavam durante o dia. Como já anunciado, os arranjos eram simétricos, entre pratos, xícaras, copos, tudo organizado em simetria. Esses detalhes foram importantes para conhecer e entender a sua narrativa, que se apresentava como um conjunto de memórias em consenso, muito organizadas e sem tensões, como se põe uma mesa. A simetria foi desdobrada na própria narrativa, na forma como apresentou a história. A família era perfeita, bonita e mesmo em tempos de mal-entendido, comuns em todas as famílias, o final era feliz. Era uma narrativa lisa, sem obstruções ou qualquer textura áspera.

Ele falou da mãe com um grande afeto e do pai com uma imensa admiração. Diz que seu pai sempre foi muito honesto e verdadeiro, e nunca reclamou de nada na vida. Tudo estava bom! Ele descreveu seu pai da seguinte forma: 
Meu pai é muito bom. É muito engraçado, um amigo que não reclama de nada da vida, não reclama nada, nada, nada [...] Ele é um homem bom, muito bom. Mas assim ó... eu tenho muito respeito por ele, sabe? E ele sempre foi assim desse jeito mais intolerante, brabo, se não fazer as coisas certas com ele... com ele assim, não tem meio certo. Tem que ser certo, tem que ser certo! (fala bem sério). Não pode ser meio certo. Então, mas acho que ele não tá errado, é assim que fui criado e respeito muito ele. Quando era criança eu sempre tive muito medo dele.

O Sr. Ademir começou cedo no mundo do trabalho, contra a vontade do pai, mas com o argumento de que tinha de empreender a sua própria vida. Precisava consumir coisas como os rapazes mais velhos e não podia ficar dependendo financeiramente dos pais por muito tempo. Senhor da própria vida desde muito jovem, narra-se filho de uma família modesta com valores cristãos, ainda que ele não fosse muito presente em todas as atividades da igreja. Não se esquece de falar da cumplicidade entre os seus pais, lembra com carinho da irmã caçula e ressalta a importância da união entre eles.

A narrativa de Sr. Ademir nessa eclusa de memória é linear, organizada e sem conflitos. Ele e a irmã crianças e depois adolescentes e jovens, o pai e a mãe presentes, o pai muito rígido, mas por vezes engraçado e a mãe muito carinhosa. Uma vida sem conflitos e, em uma exceção diante de um problema de saúde muito sério da irmã, ele lembra dos pais muito próximos, o padre em casa e ainda que assustados, havia um berço acolhedor muito presente em sua narrativa. Plasticamente foi dada à narrativa de memória nessa eclusa uma textura lisa, sem grandes problemas ou tensões. Ele se narra um rapaz cheio de vida, trabalhando, indo às festas do bairro, amante dos esportes estava sempre de bicicleta, flertando com as meninas da sua idade até que conheceu sua atual mulher, Rosane. Iniciaram um namoro ainda muito jovens e de forma muito precoce e quase que ao mesmo tempo um mundo de desafios e conquistas foi se desenhando em sua vida: começou a trabalhar no emprego que gostava e se casou diante de uma gravidez. No início, o pai o ajudou a construir uma pequena casa na propriedade da família, mas o desafio era construir uma casa maior, em um lote próprio, para a sua nova família. E no auge dessas conquistas e novas metas começou a sentir os primeiros sintomas da Esclerose Múltipla.

\section{A segunda eclusa}

A partir desse momento, sua narrativa mudou de textura e tornou-se dificil manter a organização plástica lisa. Até aqui ele se narrou um jovem confiante, cheio de desejos, possibilidades de futuro com a paternidade e em um emprego que gostava. Mas os sintomas da EM o colocaram diante da tensão com essa biografia. Ele relata a experiência com os primeiros sintomas:

[...] eu e minha esposa almoçamos, aí falei assim pra ela: vamos tirar uma sonequinha, vamos? Depois do almoço, eu estava muito cansado, eu sei que estava diferente, não estava bem [...] a gente foi e eu dormi tão rápido! Mas eu dormi e senti assim um calorão, quando eu acordei todo suado, todo molhado e eu estava com meu corpo todo dormente, as pernas e os braços muito dormentes. Tudo espinhando, achei tudo aquilo muito estranho, eu fiquei preocupado assim, na hora. Quer dizer, eu não fiquei preocupado... pensando que aquilo ia passar mais tarde. E chegou a noite, chegou outro dia nada de passar. Falei para a Rosana, falei pros meus pais, ficaram preocupados também, aí chegou na segunda feira a noite nada e tudo que eu tocava começava a espinhar mais ainda. Estava forte, ai fiquei desesperado, aí bateu aquela aflição, sabe?

Assim começaram os sintomas e a partir dessa aflição de não reconhecer mais as reações do próprio corpo, ele foi buscando ajuda em consultórios médicos. O Sr. Ademir passou 
nove anos sem diagnóstico, buscando razões para seus sintomas em consultórios das mais diversas especialidades. Cada diagnóstico fracassado, seguido de tratamentos ineficientes, confirmavam a confusão acerca do reconhecimento do seu próprio corpo. Ele fazia um duplo movimento, por um lado se deparava com a condição de infância, apontada por Agamben (2005), uma incapacidade de interpretar os signos do próprio corpo, em uma experiência babélica, como uma privação da linguagem. Nada fazia sentido para um corpo jovem e até agora muito saudável. Por outro lado, como um terminal consumidor, como descreve Guattari e Rolnik (1999), entendendo-se individualizado e filiado aos discursos médicos, como saída para a leitura daqueles signos, passou a consumir as expectativas dos consultórios, exames e afins. Como um homem, um campo de subjetividades marcado pelas necessidades do seu tempo histórico vivido e modelado no registro do social, o Sr. Ademir se frustra a cada consultório durante nove anos. Uma busca cansativa que o levou a um quadro depressivo e em um dado momento ele diz: "[...] aí dei um tempo. Fiquei assim, acho que fiquei sem procurar médico uns 3 meses, sabe? Me deu um tipo assim... um... como que se fala quando está desanimado? [...] Depressão. É isso, uma depressão, tristeza... é ui!"

Ao mesmo tempo, experimentando os mais diversos constrangimentos sociais: caía sem motivos aparentes tanto no trabalho quanto de bicicleta na rua; seu trabalho na loja de peças de automóveis exigia que ele subisse em escadas e essa atividade foi ficando comprometida; os amigos riam do seu descontrole e impotência em situações comuns para um rapaz jovem; era acusado de ir ao trabalho bêbado; não conseguia carregar peso; não conseguia controlar a fadiga no trabalho e se sentia muito envergonhado. Ele narra um episódio que o deixou muito constrangido:
[...] eu tinha muita queda, sabe? Eu adorava andar de bicicleta, adoro, adoro, adoro! [...] Deixava o carro em casa e ia trabalhar de bicicleta. Só dia de chuva daí ia de carro. Eu ia de bicicleta de tanto que eu gostava de andar de bicicleta. Aí comecei a cair. Cair de bicicleta. Perdi o equilíbrio... eu estava pedalando, aí se eu tivesse pedalando e olhasse um pouquinho pro lado eu perdia o equilíbrio e caía. Isso foi várias vezes. Várias vezes. Não podia olhar nada pro lado que eu perdia o equilíbrio e caía. Tinha que olhar só pra frente, ter visão fixa assim pra frente. Até teve um dia uma vez que estava vindo do serviço nessa ciclovia aqui do Espinheiros (bairro da cidade de Joinville), teve um cara que estava indo, um cara assim bem forte (riu), bem gordo, estava indo assim bem rápido. Trabalhava na Tupy (indústria local). Estava muito rápido e eu estava vindo pra casa. Eu estava vindo e ele estava indo. Aí naquela eu fui pra cá ele foi também, eu fui pra lá ele foi também. Daí a gente se "escorrou", junto, de frente um com o outro (risos) Meu Deus do céu! Aí caímos os dois (riu). Eu fiquei "estarrado" no chão e o cara pegou a bicicleta e se mandou. Continuou, de certo foi para a Tupy e eu fiquei ali "estarrado" no chão. Ainda bem que teve um cara que me conheceu e parou e ele tinha uma Saveiro e pegou minha bicicleta jogou em cima da Saveiro e me trouxe até em casa [...] Eu tive muita queda de bicicleta e eu ficava pensando... Meu Deus! Essas quedas, eu pensava que era tudo por causa da labirintite... por isso... era Esclerose Múltipla. ${ }^{8}$

Essa análise considerou a característica do mundo contemporâneo, de exigências rápidas, eficiência e competência no mundo do trabalho. O Sr. Ademir conta sobre uma vida de infância em que o pai era referência de "homem adulto, honesto, trabalhador e cristão", ele também conta com orgulho sobre como aprendeu acerca de uma família modesta e trabalhadora. Ele viveu em um mundo do século $X X$, do declínio de uma sociedade da produção, como aponta Bauman (2008) e ao mesmo tempo em que se

8 A partir da metodologia História Oral de Vida, optouse em manter a oralidade do entrevistado, sem correção das palavras ou ajustes de palavras não convencionais. Nesses casos foram mantidas entre aspas. 
mostravam os ares da sociedade de consumo. o labor, o trabalho era um caminho que o Sr. Ademir vislumbrava o consumo, quando ainda muito jovem decidiu trabalhar para consumir. Nas palavras dele: "eu queria trabalhar porque eu queria. Eu via os meus colegas que eram mais velhos que eu e trabalhavam, tinham seu dinheiro, aí eles compravam roupas, boné, e compravam assim todo mês, as coisinhas deles. Eu também queria". E tudo dava muito certo, o consumo, as festinhas, uma namorada, um novo emprego onde se encontrou e quando tudo parecia estar em seu domínio, os sintomas vieram e o deixaram em frustrações das mais diversas.

Bauman afirma que essa passagem da sociedade de produtores para a sociedade de consumidores se deu em uma "velocidade e o ritmo acelerado desses processos foram e continuam a ser tudo, menos uniformes" (2008, p. 15). Não existe estabilidade nesse processo e isso se exacerba na condição de um sujeito doente. Bauman diz que:

[...] a preocupação de garantir a 'vendabilidade' da mão-de-obra em massa é deixada para homens e mulheres como indivíduos (por exemplo: transferindo os custos da aquisição de habilidades profissionais para fundos privados - e pessoais), e estes são agora aconselhados por políticos e persuadidos por publicitários a usarem seus próprios recursos e bom senso para permanecerem no mercado, aumentarem seu valor mercadológico, ou pelo menos não o deixarem cair, e obterem o reconhecimento de potenciais compradores. $(2008$, p. 16$)$

E como fruto do seu tempo, o Sr. Ademir convenceu-se a criar uma empresa na expectativa de que a autogestão o retirasse das situações constrangedoras, mas sua saúde estava bastante debilitada, para tanto esforço e estresse, e, em pouco tempo, o negócio faliu. “Daí não estava bom, bateu aquela depressão danada. Não sabia o que eu tinha, emagrecendo... não conseguia dormir... não conseguia comer... uma situação muito difícil".
O que fez o Sr. Ademir, mesmo que inconsciente, para ultrapassar essa eclusa? Foram momentos em que o desamparo ficou explícito. Quando enfim o diagnóstico veio, ele já estava com um sentimento de fracasso muito grande e narrou esse momento como um "grande alivio", porque finalmente ele tinha uma explicação social para a sua condição. Porém, essa condição o levou, dois anos mais tarde, à aposentadoria muito jovem e o colocou em uma outra situação que foi o atestado de "invalidez". Essa palavra ele pronunciou pausadamente "in-va-li-dez". Nas palavras dele:

Em 2005, fiquei sabendo que era Esclerose Múltipla e me aposentei dia 17 do 7 de 2007. Aposentado por in-va-li-dez. [...] essa época foi uma sensação de alívio! Bah! Graças a Deus acharam, acharam o que eu tenho. Por que até então eu vivi desde 96 até 2005, vivia naquela incerteza, tratando de doenças, tomando remédios sem saber o que tem, viver caindo, viver tonto.

Nesse ponto sincrônico aos sintomas da Esclerose Múltipla e com a busca pelo diagnóstico, ele reconta os momentos de sofrimento com os sintomas da EM, justamente aqueles que provocam texturas na sua biografia, mas, em seguida, como se quisesse concertar essa plasticidade dizia:

Graças a Deus, passou! E hoje é assim, por isso eu agradeço a Deus. Foi difícil, foi muito dificil, mas passou. Hoje eu estou bem acomodado. Estou bem confortável. No ar condicionado, numa cama maravilhosa, colchão bem bom [...] Então, hoje é bem tranquilo, graças a Deus. Eu não posso ficar reclamando da vida.

O uso dessas expressões durante toda a narrativa da segunda eclusa, mostra uma não autorização para reclamar ainda que estivesse diante dos períodos mais dificeis de sua vida. Supomos uma identificação com a forma paterna de encarar a vida, nunca reclamando de nada, ou ainda a aproximação com os valores religiosos. Ele indicou em sua narrativa mo- 
mentos de muito sofrimento com os sintomas, sem o diagnóstico e por vezes teria ficado depressivo, mas sempre com o cuidado de dizer que tudo havia passado, graças a Deus. Como se o presente tivesse oferecido a ele uma distância do sofrimento e os detalhes não fossem mais possiveis de ver, tornando a graça recebida em primeiro plano.

Com essa estratégia narrativa, ele resolve também as fissuras de sua biografia. A plasticidade lisa que havia marcado a primeira eclusa se tornou impossivel de ser mantida na memorização desses momentos. E a cada textura enrugada, crespa, que aparecia com o sofrimento, as depressões, os afetos, como raivas, constrangimentos, era, no tempo presente, ressignificada com a afirmativa de que tudo havia ficado bem. O Sr. Ademir caminha com ajuda de muletas e ainda cai algumas vezes. Ele narrou uma queda recente, na cozinha, e no dia de uma das entrevistas sofreu um acidente causado por um desequilíbrio que o fez prender um dos dedos na porta, mas algo aconteceu, que ele diz estar tudo bem. Ele ressignificou sua condição e trouxe uma plasticidade lisa novamente para a narrativa da sua vida no presente.

\section{A chave da comporta e o fluxo da terceira eclusa}

A narrativa de Sr. Ademir mostra que sua vida, no momento sincrônico aos sintomas da doença, diante da experiência de desamparo, quando suas expectativas de futuro foram borradas, enquanto ele buscava um diagnóstico, em um consultório médico e outro, foi marcada por tensões, depressões e emoções negativas de toda ordem. Algo aconteceu que retirou o Sr. Ademir desse lugar. Essa análise mapeou quatro situações que ele mobilizou para sair da condição depressiva que a doença the impôs, algo que funcionou como uma chave. Primeiro, ele recebeu o diagnóstico e a norma do conhecimento médico, o discurso que explicou o que acontecia em seu corpo. Esse discurso tanto concedeu a ele uma explicação social para o enigma daqueles sintomas, quanto o limitou em uma patologia que o levou posteriormente a se aposentar por invalidez. Mas, em um primeiro momento, o discurso médico que o fez codificar os sintomas do seu corpo e o retirar da condição desconcertante da infância linguística de não conseguir ler um sinal, ofereceu a ele uma chave libertadora. Foi como se o liberasse para outras atitudes que o levariam a seguir o fluxo de sua vida e prospectar futuros.

Em uma segunda situação, Ademir inspirouse em outros discursos que apareceram nas narrativas da primeira eclusa. Como se Ademir projetasse em si mesmo a imagem do pai que ele tanto admirava. Um homem honesto, cristão, pai de família e que nunca reclamava das adversidades. "Eu não posso ficar reclamando da vida", ele disse algumas vezes. Assim como descreveu sobre o comportamento de seu pai, esse gesto o mobilizou a sair desse lugar de sofrimento e se projetar a partir dali.

Uma terceira situação funcionou como chave para Ademir sair do lugar de "assujeitado" à condição depressiva que a patologia limitadora o apresentou. Ele narra o cuidado de sua esposa, Rosane: “[...] a Rosane soube que eu tinha isso, aí eu vi que me abraçou com as duas mãos mais ainda. Eu vi que ela não queria sofrimento. Ela me deu mais amor ainda, começou a cuidar mais de mim". A ideia de família que Ademir narrou na primeira eclusa fez muito sentido nesse momento, um lugar como um berço acolhedor e a sua companheira de vida, assim como foi sua mãe para seu pai. Ele conta que antes de saber da doença se via muito cheio de si e confessou, timidamente, que por algumas vezes havia brigas do casal por ciúmes, mas depois da EM ele mudou a forma de perceber o casamento e a família. 
E um quarto ponto e talvez o fundamento de todos os demais é a fé de Sr. Ademir, seus valores religiosos. Ainda que no período anterior à doença ele se narra afastado dos rituais religiosos, foi a partir da EM que a fé se tornou algo indispensável ao cotidiano de sua família. Em sua narrativa, ele disse que a educação que recebeu foi católica, mas ele não era assíduo antes da doença: "depois que eu fiquei sabendo da esclerose, eu me apeguei mais com Deus, e mudou bastante, bem diferente, isso que está me dando mais forças pra enfrentar, pra não desanimar".

Esses valores religiosos, aliados ao abraço e ao acolhimento da sua esposa, dispara o comportamento do "bom homem", inspirado na imagem de seu pai. Ademir transformou o afeto do desamparo em afetos de medo e de esperança. Tanto os afetos de medo como os de esperança acionam a expectativa de futuro, já o desamparo é como não poder dizer sobre o futuro. E ele narra sobre seus medos no tempo diacrônico à doença. Quando perguntado sobre as razões de suas depressões, ele diz:

Não sei... eu sempre assim oh... eu penso muito no futuro, aí, no futuro, eu ficava sempre pensando que o pior ia acontecer pra mim. [Entrevistadora: e o pior é o quê?] o pior é eu ficar na cadeira de rodas, e não poder sair mais pra lado nenhum. Se eu ficasse trancado dentro dessa casa eu acho que logo, logo, eu estaria morto. Eu gosto de sair sabe? Eu não consigo andar, eu não consigo ir a pé daqui do meu portão ali na esquina. Até posso ir, mais aí não consigo mais voltar. [...] Assusta! Por que tenho medo que o pior possa acontecer, sabe? E a Rosane sabe disso, só que ela falou: não tem que se preocupar, a gente está junto nisso. Não se preocupa com isso. Ainda bem que ela me ajuda bastante assim.

A possibilidade de depender de cadeiras de rodas ou piorar suas condições de mobilidade provoca o afeto do medo no Sr. Ademir. Ele se narrou um rapaz ágil, que gosta de ati- vidade física, bicicleta, futebol. Ele crê que se ficar sem mobilidade para sair de casa, logo, logo, estaria morto. Ele caminha pouco e o medo de não conseguir voltar e essa condição o faz sentir sua vulnerabilidade e a precariedade da sua vida. Ele mobiliza as suas sensações de tempo, quando lembra do passado sem a doença e projeta um futuro com a EM, que está retirando dele a mobilidade. Como ele resolve essa questão? Quando ele aciona suas crenças religiosas e se sente acolhido pela sua esposa, ele faz um desdobramento do afeto do desamparo e o transforma em medo e esperança. Ele entrega sua demanda em uma confiança na Rosane e em Deus, e se torna um homem nos critérios que ele admira em seu pai, correto, sem mentiras, honesto, fiel à esposa.

Ele fala de esperanças, fala da sua medicação que o ajuda a retardar a progressão da doença e agradece a Deus por isso, desejando que em um futuro a ciência consiga achar uma cura para a EM. Até lá, ele se alimenta da esperança que sua mulher e Deus oferecem, de que estará tudo bem. Hoje, o Sr. Ademir fica em casa sozinho durante o dia, enquanto a esposa e as filhas trabalham, e ele cuida da estrutura doméstica, onde se tornou indispensável ao núcleo familiar. Assim, ele corrige o sentido da palavra "inválido". O diagnóstico trouxe a ele a possibilidade de ressignificar a vida limitada, ele entrou no conforto do discurso que explicou sua condição e assim se refaz no seu cotidiano. No Brasil, o imaginário social de um homem no interior da vida doméstica é, por vezes, negativo. 0 interior da casa é um lugar menos provável para um homem se singularizar. Mas é nesse lugar que o Sr. Ademir constrói uma outra direção para a sua vida:

Invalidez! Uma palavra tão feia! Mas essa palavra não combina comigo. Eu acho que não combina comigo. Porque eu tenho grande serventia nessa casa, tanto pra minha mulher quanto pras minhas filhas. Mesmo assim, eu consigo roçar o 
gramado no jardim, limpo minha casa, faço comida. Do meu jeito, na minha velocidade, mas faço. Então, eu não me considero inválido.

Quando está com fadiga e não se sente bem, ele assiste a programas de cozinha e foi assim que aprendeu as primeiras receitas que executa. Para além dessas receitas prontas, inventa novas, com as frutas do quintal, faz um cardápio para o gosto de cada uma das três mulheres de quem se sente cuidador; inverte assim a condição de cuidador e cuidado e se singulariza nesse microespaço familiar. O Sr. Ademir não aceitou a norma que o colocou como inválido, mas construiu a partir dela e das suas condições de vida anteriores à doença (valores, crenças religiosas, sentidos de família) uma normatividade para a sua vida. Sua narrativa voltou a apresentar a plasticidade lisa que buscou desde o início dos relatos, a simetria, a organização.

A observação de que ele nos recebia com a mesa posta, sempre com uma organização simétrica, parece fazer parte da forma da vida do Sr. Ademir. Sua narrativa trazia também uma organização: apesar das adversidades, a família ficava sempre unida, tanto seus pais e irmã, quanto a família que ele construiu para si. Apesar de todos os traumas com a doença, ele não se permitiu reclamar, antes, voltou para igreja, não reclama de nada e procura seguir os preceitos do que entende por um "bom homem", assim como vê a imagem de seu pai. Concordando com Le Blanc (2007), essa análise termina reforçando o argumento de que a vida não cabe na limitação de uma norma, mas ela mesma é um jeito de viver as normas em diálogos vivos consigo mesmo, uma subjetivação em movimento.

L'immanence du vivant à la vie le conduit à appréhender sa vie en termer de normes. Ce qui revient à dire qu'un individu, au fond, ce n'est rien d'autre qu'une certaine façon de se confronter aux normes dans le débat incenssant que le vivant entretient avec sa propre vie. ${ }^{9}$ (LE BLANC, 2007, p. 63)

\section{Algumas reflexões}

Os discursos médicos e terapêuticos sobre a Esclerose Múltipla explicam a doença, definem o sujeito doente, a partir de uma norma, e oferecem uma segurança diante das incertezas dos sintomas. Diante da insegurança que causou a ausência de diagnóstico na vida do Sr. Ademir, a informação acerca da doença, as normas médicas apareceram como libertadoras para o retorno às rédeas da própria vida.

As narrativas sincrônicas à doença foram paralisantes para o Sr. Ademir. Essa eclusa foi o momento do trauma. Em sua narrativa, ficou muito clara a sua filiação de sentidos do que era normal e saudável e, todos os seus sintomas, que ficaram sem explicações por nove anos, o colocavam na condição de anormal. Apenas quando a "válvula" das expectativas de futuro foi aberta é que se tornaram possíveis as narrativas diacrônicas. Mas o que fez Sr. Ademir abrir essa expectativa de futuro? Em todas as narrativas, consciente ou inconsciente, foi algo referencial da primeira eclusa, do passado anterior à doença. Os valores cristãos que anteriormente não eram tão importantes formam retomados, a imagem de homem de valor que ele trouxe do pai, os sentidos de família, que ele narrou muito claramente em suas memórias de infância, e o acolhimento de sua esposa amalgamados, se tornaram chaves para que ele pudesse abrir as comportas da eclusa sincrônica à doença e ressignificar a sua vida. Os passados vividos antes da doença foram fundamentais à elaboração dos sentidos sobre ela.

9 Tradução livre: A imanência do vivente para a vida leva-o a apreender sua vida em termos de normas. O que é dizer que um indivíduo, em essência, não é senão uma certa maneira de confrontar as normas no incessante debate que os vivos têm com sua própria vida 
Durante toda a análise, a pergunta sobre a existência de uma consciência comum sobre a Esclerose Múltipla foi perseguida. Esse artigo trouxe apenas a análise de uma narrativa, no entanto, ela estava em consonância com as demais. Sim, existe uma consciência comum sobre a doença, porque ela vem dos discursos médicos e farmacêuticos, que oferecem uma norma sobre a doença. A partir do momento que esse corpo não se configura mais como normal, ele possui algumas características comuns aos demais doentes. Essa verdade é consumida e parafraseada nas narrativas. Frases como "somos sistemáticos", "somos perfeccionistas" aparecem sempre, remetendo a uma verdade médica sobre a doença.

Porém, as experiências individuais vividas antes da doença chegar: os valores, os hábitos de família, as percepções de mundo, as subjetividades em movimento foram fundamentais

\section{Referências}

AGAMBEN, Giorgio. Infância e história. Destruição da experiência e origem da história. Tradução de Henrique Burigo. Belo Horizonte: UFMG, 2005.

BAUMAN, Zygmunt. Vida para consumo: a transformação das pessoas em mercadorias. Tradução de Carlos Alberto Medeiros. Rio de Janeiro: Jorge Zahar, 2008.

CANGUILHEM, Georges. 0 normal e o patológico. Tradução de Maria Thereza Redig de Carvalho Barrocas. 6. ed. Rio de Janeiro: Forense Universitária, 2009.

DELORY-MOMBERGER, Christine. A pesquisa biográfica ou a construção partilhada de um saber do singular. Revista Brasileira de Pesquisa (Auto)Biográfica, Salvador, v. 01, n. 01, p. 133-147, jan./abr. 2016. Disponivel em: <https://www.revistas.uneb.br/index.php/rbpab/article/view/2526/1711>. Acesso em: 20 dez. 2016.

GUATTARI, Félix; ROLNIK, Sueli. Micropolítica. Cartografias do desejo. 5. ed. Petrópolis, RJ: Vozes, 1999.

KOSELLECK, Reinhart. Estratos do tempo. Estudos para a elaboração de sentidos diferenciados na vida prática. O que fazer com a doença? Somá - la com a depressão ou construir-se um outro a partir dela. As normatividades possiveis. E esse construir-se um outro se dá nas microrrelações. Nas cinco histórias narradas não apareceu, por exemplo, nenhum feito extraordinário, continuaram a fazer o que sabiam, mas significando e adaptando a doença de outra forma.

Em outro caminho, observou-se que a doença mudou a consciência de si. A partir da doença, os passados foram revistos algumas vezes. No caso do Sr. Ademir, foi motivo para voltar à igreja, reconciliar o casamento, mas em outros casos foi também momento para pedir perdão aos pais, rever posturas como pai, se afirmar ateu, reelaborar sentidos de espiritualidade, mudar prioridades de vida. A todas essas mudanças foi creditada sua razão à doença, um outro de si mesmo.

sobre História. Tradução de Markus Hediger. Rio de Janeiro: Contratempo, 2014.

LE BLANC, Guillaume. Canglilhem et les normes. Paris: Presses Universitaires de France, 2007.

MUSEU DA PESSOA. Tecnologia social da memória. São Paulo: Fundação Banco do Brasil, 2009.

RICOEUR, Paul. La lectura del tiempo pasado: memória y olvido. Tradução de Gabriel Aranzueque, Madrid: Arrecife, 1999.

SAFATLE, Vladimir. 0 circuito dos afetos. Corpos políticos, desamparo e o fim do indivíduo. Belo Horizonte: Autêntica, 2016.

SILVEIRA, Bruna Rocha. Dor compartilhada é dor diminuída: autobiografia e formação identitárias em blogs de pessoas em condição de doença. 2016. 187f. Tese (Doutorado em Educação). Universidade Federal do Rio Grande do Sul, 2016.

Recebido em: 16.05.2017

Aprovado em: 30.10 .2017 
Raquel Alvarenga Sena Venera é Doutora em Educação pela Unicamp, 2009. Pós-doutora em Educação pela Université Lille3. Professora e Vice-coordenadora do Programa de Pós-Graduação em Patrimônio Cultural e Sociedade, professora do Curso de História, ambos da Universidade da Região de Joinville, Univille. Coordenadora do Grupo de Pesquisa Subjetividades e (auto)biografias. e-mail: raquelsenavenera@gmail.com

Universidade da Região de Joinville, UNIVILLE - Rua Paulo Malschitzki, 10 - Zona Industrial Norte Joinville - SC - 89219-710. Telefone: (47) 34619223 - (47) 996130713 